\title{
Factors Associated with Depression in Navy Recruits
}

\author{
Reg Arthur Williams, Bonnie M. Hagerty, \\ and Steven M. Yousha \\ University of Michigan
}

\author{
Kenneth S. Hoyle \\ Naval Hospital, Great Lakes
}

Hiroaki Oe

University of Michigan

The age of onset for depression is decreasing and seems to be linked with major life events. This study examined predisposing and concomitant factors related to Navy recruit basic training, and consisted of 443 recruits (200 with depressive symptoms and 243 matched comparison subjects). Two hypotheses were proposed, and both were supported by results of the study. Depressed recruits were more likely to be separated from the Navy and not complete training. They had significantly more predisposing factors than comparison recruits including family history of mental illness, family history of alcohol abuse, and history of psychiatric problems. They also had significantly more concomitant factors such as higher levels of stress, more loneliness, more life-change events, lower sense of belonging, more emotion-oriented coping, and less task-oriented coping. Although the study examined Navy recruits, the findings are applicable to depression in young people. This study adds to understanding the role of life

This research (TSNRP 96-048, MDA 905-96-Z-0025) was sponsored by the Department of Defense TriService Nursing Research Program at the Uniformed Services University of the Health Sciences. The information or content and conclusions, however, do not necessarily represent the official position or policy of, nor should any official endorsement be inferred by, the TriService Nursing Research Program, the Uniformed Services University of the Health Sciences, the Department of Defense, Department of the Navy, or the U.S. Government. The authors wish to extend appreciation to the Great Lakes Naval Recruit Command, Navy Training Center, Naval Hospital, Great Lakes, and the School of Nursing, University of Michigan, for their support of this research project. In addition, the authors gratefully acknowledge the assistance of our consultants, Drs. Yvonne Abdoo, James Coyne, Marshall Goby, Julie Horrocks, Robert MacFarland, and M. Anthony Schork. The contributions of our research team, including CDR Dorothy Engler, LCDR Bruce Stickland, LT Mark Reuillard, LT Kurt Andersen, LTJG Jeff Dortch, and Ms. Mary Hawk are greatly acknowledged.

Correspondence and reprint requests should be addressed to: Reg Arthur Williams, University of Michigan School of Nursing, 400 N. Ingalls, Room 4352, Ann Arbor, MI 48109; e-mail: rawill@ umich.edu. 
stressors, interpersonal functioning, and development of depressive symptoms. (c) 2002 Wiley Periodicals, Inc. J Clin Psychol 58: 323-337, 2002.

Keywords: depression; Navy recruits; military; stress; coping; loneliness

Depression is now recognized as a major public health problem in the United States, causing severe symptom distress and dysfunction, and has a general population lifetime prevalence of $12.7 \%$ for men and $21.3 \%$ for women (Kessler et al., 1994). Depression and its sequelae and recurrence compromise functional ability, interpersonal relationships, occupational adjustment, social roles, and personal cognition and behavior, creating costly social and economic burdens on families, communities, and society (Klerman \& Weissman, 1992).

The age of onset of depression has decreased while the risk of its development has increased threefold since the 1920s (Gershon, 1991). Its prevalence, onset at younger ages, and link with major life events are particularly relevant for young men and women who are joining the Navy and encountering recruit basic training, or "boot camp." Many of these recruits are leaving home for the first time and entering a new existence without their usual support systems. Recruits who experience depressive symptoms may forfeit a Naval career or may take longer to complete recruit training, thus incurring more training costs to the Navy. While recruit training is a major life event and potential stressor to all, it is not clear why some recruits respond with depressive symptoms while others proceed successfully. This study provides a unique opportunity to examine young men and women who are experiencing many of the same stressors at the same time, with some variables being controlled that otherwise would not be possible in other settings.

Depression has multicausal origins whereby a number of biological, social, psychological, and cognitive factors converge to cause depressive symptoms. Stress and resultant forms of adaptation have been identified as triggers of depression. Major life events can trigger the onset of depressive symptoms (Monroe \& Depue, 1991), and can exacerbate depressive symptoms in a person with a depressive history. Monroe and Depue emphasized that the relationships between life events, stress, coping, and depression are complicated but crucial for developing a more accurate theory on depression. These researchers also suggested that it would be more useful to investigate life events, stress, and depression with specific situations. This might lead to the identification of specific relationships and, ultimately, specific interventions for a person experiencing defined stressors. Predisposing and concomitant factors are elements of the stress-adaptation process, including existing characteristics, precipitating stressors, appraisal of stressors, coping resources, and coping mechanisms, which result in some type of adaptive or maladaptive coping response (Stuart, 1998).

Predisposing factors are those characteristics that will eventually influence the individual's response to stress. The predisposing factors examined in this study included family history of mental illness; a history of physical, emotional, or sexual abuse; history of depression; and history of substance abuse (Akiskal, 1989; Goodwin \& Jamison, 1990; Warner, Weissman, Fendrich, Wickramaratne, \& Moreau, 1992). 
The precipitating stressor represents the stimulus or life event that the individual encounters and that can be challenging, threatening, or demanding (Paykel et al., 1969). In this study, the precipitating stressor was Naval recruit basic training.

A concomitant factor or appraisal of the stressor is the way in which the individual perceives and understands the stressful situation. This process encompasses both cognitive and emotional responses (Cornelis, Armeling, \& deJonghe, 1989). Perceived stress (cognitive) and loneliness (emotional) (Russell, Cutrona, Rose, \& Yurko, 1984; Weiss, 1973) are components of appraisal examined in this study. Loneliness has been linked to suicide (Wenz, 1977) and depression (Bragg, 1979; Hagerty, Williams, Coyne, \& Early, 1996; Peplau, Russell, \& Heim, 1979; West, Kellner, \& Moore-West, 1986). The extent to which a person responds negatively to stress appears to be influenced by an affective response of loneliness.

Coping resources refer to options or supports that the individual has available to deal with the stressor (Stuart, 1998). For the purposes of this study, coping resources were the recruits' sense of belonging (Hagerty, Lynch-Sauer, Patusky, Bouwsema, \& Collier, 1992) and social support (Coyne \& Downey, 1991; Ganster \& Victor, 1988; House \& Kahn, 1985; Kessler \& McLeod, 1985). Disruption of environmental and social relationships is clearly linked to depression (Cornelis et al., 1989). Sense of belonging has been defined as a person's perception of valued involvement and fit within the context of any relationship. Theoretically, a person with a strong sense of belonging is better equipped to respond more adaptively to a major life event or stressor. A lower sense of belonging has been found to be the strongest predictor of membership in a depressed group (Hagerty et al., 1996). Social support has been defined as the perceived availability of helpful persons within a structured social network (Sarason, Sarason, \& Pierce, 1990), and its absence has been associated with poorer functioning, including depression (Paykel, 1994). Understanding the nature of recruits' interpersonal relationships, including sense of belonging and social support, may well illuminate specific interpersonal processes that are specifically related to a recruit's development of depression.

Coping mechanisms are actual strategies that an individual uses to manage the stress evoked by the stressor. Ineffective coping strategies have been associated with depression (Gulesserian \& Warren, 1987; Parker, Brown, \& Blignault, 1986; Rippere, 1976) and influence vulnerability to onset and course of the illness through mediating personenvironment interactions (Billings \& Moos, 1981).

One type of potential response to stress is depression, which, with its multitude of affective, cognitive, physical, and behavioral symptoms, can impair recruits' functional abilities. In the case of recruit training, the outcome can be either separation from the Navy or continuation of training to completion. Cigrang, Carbone, Todd, and Fiedler (1998) reported that Air Force recruits who were recommended for discharge had a history of depression, expressed lack of motivation for the military, had suicidal ideation, and withheld information about their mental health history. It is unclear, however, as to which predisposing or concomitant factors actually increase individual vulnerability in response to specific stressors.

This study aimed to examine what selected predisposing and concomitant factors of appraisal of stressors, coping resources, and coping strategies were predictive of the type of responses to Navy recruit training. The following research hypotheses were tested in the study. When compared with matched comparison recruits, recruits with depressive symptoms will have: (Hypothesis 1) predisposing factors of more parental abuse, more family history of substance abuse, more family history of mental illness, and more history of psychiatric problems; (Hypothesis 2) concomitant factors of more perceived stress, more life-change events, more loneliness, lower social support, lower sense of belonging, and more emotion-oriented and less task-oriented coping strategies. 


\section{Method}

The investigation used a cross-sectional, two-by-two factorial design. The two factors were depressive symptoms (whether recruits had depressive symptoms) and the disposition status (completion of recruit training or separated from the Navy).

\section{Sample}

The sample consisted of 443 recruits in basic training at the Navy Recruit Training Command at Great Lakes, Illinois. Males comprised $74 \%$ of the sample. The mean age of the recruits was $19.8(S D=2.7)$, with $80.4 \%$ single, $12.8 \%$ engaged, $5.0 \%$ married, $1.6 \%$ divorced or separated, and $0.2 \%$ widowed. The majority were Caucasian $(67.5 \%)$, followed by African American (16.7\%), Hispanic (5.9\%), Native American (4.3\%), Asian $(2.7 \%)$, and other ethnic groups $(2.9 \%)$. This distribution for the ethnic background was consistent with that of the Navy's active-duty population, $\chi^{2}(3, N=443)=4.69$, $p=.20$.

Of the 443 recruits, 200 (45\%) reported depressive symptoms and were classified as the depressed group. These recruits had come to the attention of the recruit training system by exhibiting depressive symptoms and were evaluated by a mental health professional prior to recruitment into the study. Recruits with depressive symptoms presented during all phases of the nine weeks of recruit training.

The remaining 243 recruits (55\%) were classified as the comparison group and were group matched with depressed recruits on age, sex, and ethnic background. No significant differences existed between these groups regarding the demographic characteristics.

Recruits with depressive symptoms were purposively sampled from a Recruit Evaluation Unit, in-patient psychiatric unit, or the Separation Unit. All recruits with depressive symptoms who had come to the attention of the system were potential subjects.

The comparison group recruits were obtained from two sources. The first source comprised 56 recruits who had developed a medical condition that removed them from Navy basic training (such as cellulitis from a foot blister, an orthopedic injury, rubella, or varicella). The second source consisted of 187 recruits who were actively in training without any preexisting conditions. These comparison recruits were administered a structured clinical interview screening questionnaire to assure that they did not meet criteria for any current or past psychiatric illness. There were no statistically significant differences between the two comparison groups regarding the study variables.

\section{Measures}

Demographic information of recruits was obtained and also included family psychiatric and substance use background. Interviewers recorded subjects' research psychiatric diagnoses across all five DSM-IV (American Psychiatric Association, 1994) axes. They also recorded location of data collection, disposition of the recruit (separated from the Navy or completed basic training), and subject type (recruits with depressive symptoms or matched comparisons). Comparison recruits whose data were collected as a group also completed the SCID screening questionnaire to rule out psychiatric illness. Recruits with depressive symptoms completed a SCID interview conducted by a member of the research team.

History, Opinion, Interest Form (HOI). The HOI (Bloom, 1980; Lachar, Sparks, Larsen, \& Bisbee, 1974) was completed during the basic training in-processing phase by 
all recruits as part of the Navy Air Force Medical Evaluation Test (NAFMET; Crawford $\&$ Fiedler, 1991). There are 69 true-false items assessing seven dimensions: prior history of problems with family, school, alcohol, legal system, antisocial behaviors, history of depressive symptoms, and history of mental health treatment. Predictive validity was supported by accurately predicting $95 \%$ of recruits with severe adjustment problems and $45 \%$ of recruits with drug abuse.

In-Processing Screening Questionnaire (SHIP). The SHIP is a recently developed screening tool by Naval Hospital, Great Lakes (1998), that consists of 191 questions regarding recruits' history of medical conditions. There are 17 behaviorally related questions that are scaled dichotomously (yes/no responses). The items investigate abuse history, alcohol and drug history, depression and anxiety, suicide history, and extended periods of disturbed sleep, appetite, and concentration. A $2 \frac{1}{2}$-week test-retest reliability of the instrument produced a coefficient of .98 .

Beck Depression Inventory, Second Edition (BDI-II). The BDI-II (Beck, Steer, \& Brown, 1996) is a self-report measure that consists of 21 items assessing the presence and severity of affective, cognitive, motivational, vegetative, and psychomotor aspects of depression. Coefficient alpha for the BDI-II with outpatients was .92 and with college students was .93. There is evidence of strong convergent and discriminant validity (Beck et al., 1996). The Cronbach's alpha reliability coefficient for this study was .93.

Perceived Stress Scale (PSS). The PSS is a 14 item, 5-point Likert-type scale that examines the degree to which situations within the past month are considered stressful. Concurrent and predictive validity have been reported. The internal consistency of the instrument was an .85 coefficient alpha (Cohen, Kamarck, \& Mermelstein, 1983). The Cronbach's coefficient alpha for this study was .89 .

Revised UCLA Loneliness Scale (RULS). This 20 item, self-report measure examines degree of loneliness, abandonment, and lack of sociability. A high internal consistency is evident with .94 coefficients alpha across several studies (Hagerty \& Patusky, 1995; Russell et al., 1984). The Cronbach's coefficient alpha for this study was .94. Russell and colleagues have cited evidence of strong construct, concurrent, and discriminant validity.

Sense of Belonging Inventory (SOBI). Sense of belonging is the experience of personal involvement in a system or environment such that one feels an integral part of that system or environment (Hagerty et al., 1992). The SOBI consists of two separately scored scales: 15 items measuring the antecedent conditions for sense of belonging (SOBI-A) and 18 items measuring the psychological experience of sense of belonging (SOBI-P). The SOBI-P has a Cronbach's alpha of .93 whereas the SOBI-A has a Chronbach's alpha of .73 (Hagerty \& Patusky, 1995). Cronbach's coefficient alpha for this study was .96 for the SOBI-P and .83 for the SOBI-A. Content and construct validity also have been demonstrated (Hagerty \& Patusky, 1995).

Interpersonal Relationships Inventory (IRI). The IRI is a 39-item measure that assesses level of perceived social support, reciprocity, and conflict using a 5-point, Likert-type scale. Cronbach's coefficients alpha were .92 for social support, .83 for reciprocity, and .91 for conflict (Tilden, Nelson, \& May, 1990). Coefficients alpha for the subscales in this study were .91 for social support, .87 for reciprocity, and .86 for conflict. Criterion validity has been established (Tilden et al., 1990). 
Attachment Style Questionnaire (ASQ). This 40-item questionnaire assesses attachment styles across five dimensions in two categories: Secure (Confidence) and Insecure (Discomfort, Need for Approval, Preoccupation with Relationships, and Relationships as Secondary) based on conceptual definitions of Bowlby $(1969,1982)$ and Ainsworth (1973). The coefficients alpha reliabilities ranged from .76 to .85 for the five dimensions (Feeney, Noller, \& Hanrahan, 1994). For this study, the Cronbach's coefficients alpha ranged from .71 to .85 . Using the two dimensions, the coefficient alpha was .85 for both Secure and Insecure attachment styles.

Coping Inventory for Stressful Situations (CISS). This 48-item inventory measures three major coping strategies used during stress: task-oriented coping, emotion-oriented coping, and avoidance-oriented coping (Endler \& Parker, 1990a, 1990b). The avoidanceoriented scale is divided into distraction and social diversion subscales. Endler and Parker (1990a) reported coefficients alpha ranging from .69 to .92 for the various scales on a variety of samples including "normal" adults and psychiatric patients. Six-week testretest correlations range from .51 to .73 . The coefficients alpha for this study were as follows: task oriented coping $=.93$, emotion-oriented coping $=.91$, avoidance-oriented coping $=.84$, distraction $=.81$, and diversion $=.83$.

List of Threatening Experiences (LTE). Brief life events scales have been found to account for substantial portions of adversity. Brugha and Cragg (1990), who described good reliability and validity for the questionnaire, have examined the LTE based on the original work of Holmes and Rahe (1967). Factors include such items as loss of employment, loss of a loved one, and development of a serious illness. This list of 12 threatening life experiences demonstrated good test-retest reliability (Cohen's kappa 0.24-1.0, with 11 of the 12 above .78). Sensitivity of the questionnaire was 0.89 and specificity of 0.74 for events six months prior to data collection.

Structured Clinical Interview for DSM-IV (SCID). The SCID is a semistructured interview for helping determine a DSM-IV Axis I diagnosis. Approximating the DSM-IV decision trees, the SCID allows systematic examination of diagnostic criteria for each disorder. The kappas for the Axis I SCID diagnoses have ranged from .57 to .92 (Cohen, 1960; Robins, Helzer, Croughan, \& Ratcliff, 1981; Spitzer, Williams, Gibbon, \& First, 1990). The interrater reliability for this study was $92 \%$.

SCID Screen. This abbreviated computerized version of the SCID (First, Gibbon, Williams, \& Spitzer, 1995) is used as a screening device to assess Axis I psychiatric disorders. Validity studies on the SCID Screen show kappa coefficients averaging $\mathrm{\kappa}=$ .77. Interrater reliabilities have ranged from 82 to $100 \%$ (Segal, Hersen, \& Van Hasselt, 1994; Williams et al., 1992) depending on the diagnostic population evaluated.

Computer Assisted Structured Interview for Axis II Diagnoses (CAS-II). The CAS-II is a computerized version of the SCID-II (First, Gibbon, Spitzer, Williams, \& Benjamin, 1997). It provides a decision-tree format of questions to help the examiner assess for Axis II (personality) psychiatric disorders. Kappas for the SCID-II were similar to testretest kappas reported for other personality assessment instruments (Loranger, 1988; Skodol, Rosnick, Kellman, Oldham, \& Hyler, 1988).

GAF Report. The GAF report is a computerized, decision tree-based program used to determine subjects' global assessment of functioning over the past three months by 
rating from 1 to 99 to determine degree of functionality of a given individual (First Multi-Health Systems, 1996). The GAF has intraclass correlation coefficients for admission for raters of .58 to .81 (Hall, 1995; Jones, Thornicroft, Coffey, \& Dunn, 1995). The GAF has shown concurrent validity with depression (Hall, 1995) and the Psychiatric Symptom Assessment Scale (Roy-Byrne, Dagadakis, Unutzer, \& Ries, 1996).

\section{Procedure}

Following appropriate human subject approval and securing informed consent, HOI and SHIP scores of participating recruits were extracted from the Navy's database. Staff were educated about the study and assisted with subject recruitment. Members of the research team were trained to use the SCID by two of the investigators. Training was conducted over a three-day period using training procedures recommended by Spitzer et al. (1990). Interrater reliability was assessed by having research team members observe a SCID interview and independently score the SCID.

Exclusion criteria for recruits were if they exhibited behaviors that suggested a psychotic disorder or had a significant alcohol or drug abuse history. No recruits were excluded from the study, and less than one percent of the recruits refused participation.

Comparison recruits were group-matched with the depressed recruits on age, sex, and ethnicity. These recruits were administered a SCID interview or completed the SCID screening questionnaire to assure that they did not meet criteria for any current or past psychiatric illness. It was not possible to conduct the full SCID interview with all comparison recruits due to lack of time in their training schedules. Comparison recruits were excluded from the study if they screened positive for a possible major psychiatric disorder. They also were given the same packet of tests as the depressed recruits. Disposition of all recruits (completed recruit training vs. separated from the Navy) was obtained later.

\section{Results}

Among the 200 recruits with depressive symptoms, 37.5\% met the research diagnostic criteria of Major Depressive Disorder, which was the most frequent primary Axis I diagnosis. Of the remaining recruits, 32\% met Adjustment Disorder with Depressed Mood criteria as the second most frequent diagnosis while $16.5 \%$ had Dysthymia, $5.5 \%$ had Bipolar Disorder, and 5.5\% had other Axis I diagnoses. Three percent of the recruits had depressive symptoms, but did not meet criteria for one of the research diagnoses. In addition, $17.5 \%$ of the depressed recruits had Axis II (PDs) research diagnoses. Over half of these recruits met criteria for Borderline Personality Disorder. There were 38 depressed recruits who were initially returned to training, but only 23 successfully completed the program. In the depressed group, recruits who completed training met criteria for one of the following research diagnoses: 65.2\% (15 recruits) for Adjustment Disorder with Depressed Mood or with Mixed Disturbance; 13\% (3 recruits) for Major Depressive Disorder; $4.3 \%$ (1 recruit) for Disorder Diagnosed in Infancy, Stuttering, whereas $17.5 \%$ (4 recruits) experienced subclinical depressive symptoms, not meeting criteria for a research diagnosis.

The percentage of females in this sample $(25.7 \%)$ was an overrepresentation of the usual percent of females at Great Lakes Naval Training Command (12-15\%). There were no significant differences between the female and the male recruits in both the depressed and the comparison groups on the major variables in the study. Moreover, there was no significant association between the number of female recruits and male recruits with or without depressive symptoms. 
Hypothesis 1 was concerned with the history of parental abuse, substance abuse, family mental illness, and psychiatric problems. These mental health background questions were selected from individual items from the Background questionnaire, the SHIP, and the HOI. As the first step, all the predisposing factors were examined. As seen in Table 1, the depressed group had significantly more history of these predisposing factors than the comparison group. As a second step, the relative strengths of these factors were examined in a logistic regression model. Variables were entered into the logistic regression using the block method $(\log$ likelihood $=67.6, d f=3, p=.0001)$. As depicted in the odds ratio, depressed recruits were 3.8 times more likely than comparison recruits to have a family history of mental illness (Wald $=10.2, p<.001$ ), 3.7 times more likely to have a family history of alcohol abuse (Wald $=13.3, p<.001$ ), and 2.0 times more likely to have psychiatric problems (Wald $=14.3, p<.001$ ). The logistic regression based on a predictive value probability of .25 as a decision border was used to determine group classification (Weinstein \& Fineberg, 1980). The logistic regression model resulted in a sensitivity of $82 \%$ and a specificity of $60 \%$, correctly classifying $69 \%$ of recruits. Having a history of psychiatric problems and family histories of mental illness and alcohol abuse moderately affect the odds for representing depressive symptoms. Therefore, Hypothesis 1 was supported by the data.

Table 2 presents mean scores of the variables for each group. As expected, the depressed group showed BDI scores three times higher and PSS scores almost two times higher than did comparison recruits. The depressed group was significantly different from the comparison group in most of the study variables.

To test Hypothesis 2, appraisal of stressors, coping resources, and coping strategies were examined for the depressed and comparison groups. A logistic regression model was developed excluding the BDI and the PSS. These two variables were excluded since the depressed group was significantly different in their scores and they were highly correlated ( $r=.75$ ). According to Rawlings (1988), including the two highly correlated covariates could make the analysis unstable because small changes in the response or covariates could cause large changes in the estimated coefficients. When the primary research question is to identify important variables, then regression models using highly correlated predictor variables can be misleading. Using the same group decision probability of .25 , sensitivity of $93 \%$ and specificity of $68 \%$ with $79 \%$ classification accuracy was attained. The depressed group had greater loneliness, more life-change events, lower psychological sense of belonging, used more emotion-oriented coping strategies, and used less task-oriented coping than the matched comparison group (Table 3), thus strongly supporting Hypothesis 2.

Table 1

History of Family Substances Use, Family Mental Illness, Parental Abuse, and Psychiatric Problems of Depressed Group and Comparison Group Recruits

\begin{tabular}{lcccr}
\hline Items* History of: & \% Depressed & \% Comparison & Test Statistic & $p$ \\
\hline Family alcohol abuse & 59.3 & 24.2 & 28.2 & $<.001$ \\
Family drug abuse & 34.3 & 7.5 & 23.6 & $<.001$ \\
Family mental illness & 50.9 & 11.6 & 40.6 & $<.001$ \\
Parental abuse & 21.9 & 12.2 & 40.1 & $<.001$ \\
Psychiatric problem & 12.8 & 2.2 & 61.4 & $<.001$
\end{tabular}

*For those items that had multiple questions, contingency tables were established according to the frequency for "Yes" answers over all items. Test of homogeneity over the depressed group and comparison group recruits was then conducted. For other single items, a proportion comparison test was conducted. 
Table 2

Differences between Depressed Group $(\mathrm{n}=200)$ and Comparison Group Recruits $(\mathrm{n}=243)$ Regarding Study Variables

\begin{tabular}{|c|c|c|c|c|}
\hline \multirow[b]{2}{*}{ Measures } & \multicolumn{2}{|c|}{ Depressed } & \multicolumn{2}{|c|}{ Comparisons } \\
\hline & $M$ & $S D$ & $M$ & $S D$ \\
\hline Beck Depression Inventory (BDI) & 25.6 & 10.3 & 8.6 & 6.6 \\
\hline Perceived Stress Scale (PSS) & 35.3 & 7.7 & 20.8 & 8.5 \\
\hline Loneliness Scale (RULS) & 52.2 & 11.6 & 37.4 & 10.7 \\
\hline \multicolumn{5}{|l|}{ Sense of Belonging Inventory } \\
\hline Psychological (SOB-P) & 46.1 & 10.9 & 60.2 & 9.9 \\
\hline Antecedents (SOB-A) & 42.7 & 6.3 & 45.5 & 6.0 \\
\hline \multicolumn{5}{|l|}{ Interpersonal Relationship } \\
\hline Social support & 48.3 & 9.3 & 54.3 & 8.0 \\
\hline Reciprocity & 47.4 & 7.9 & 51.1 & 7.6 \\
\hline Conflict & 39.9 & 7.6 & 33.8 & 8.6 \\
\hline \multicolumn{5}{|l|}{ Attachment Styles } \\
\hline Secure & 28.2 & 7.9 & 35.0 & 6.7 \\
\hline Insecure & 120.4 & 19.3 & 100.7 & 20.3 \\
\hline \multicolumn{5}{|l|}{ Coping Inventory (CISS) } \\
\hline Task-oriented & 48.4 & 11.2 & 58.5 & 10.6 \\
\hline Emotion-oriented & 54.0 & 9.7 & 39.5 & 11.5 \\
\hline Avoidance-oriented & 50.0 & 10.0 & 50.8 & 11.1 \\
\hline Distraction-oriented & 23.0 & 6.1 & 21.8 & 6.9 \\
\hline Diversion-oriented & 17.3 & 4.5 & 19.0 & 4.3 \\
\hline Global Assessment of Functioning (GAF) & 63.1 & 14.3 & 83.7 & 7.6 \\
\hline List of Threatening Experiences & 2.5 & 1.8 & 1.4 & 1.5 \\
\hline
\end{tabular}

To further delineate the depressed recruits, they were examined according to the disposition status. The number of depressed recruits who completed training was small $(n=23)$ compared to the separated recruits $(n=177)$. To overcome this difficulty and to determine the relative strength of measurements for the disposition status, all measures were modeled together to develop a classification-tree model (Clark \& Pregibon, 1992). According to Breiman, Friedman, Olshen, and Stone (1984), the classification-tree model

Table 3

Logistic Regression Model of the Concomitant Factors for Appraisal of Stressors, Coping Resources, and Coping Strategies on Depressed Group $(\mathrm{n}=200)$ and Comparison Group Recruits $(\mathrm{n}=243)$

\begin{tabular}{lrccc}
\hline Measures & Wald & $S E$ & $\begin{array}{c}\text { Standardized } \\
\text { Estimate }\end{array}$ & $p$ \\
\hline Loneliness & 10.09 & .02 & .40 & .0015 \\
List of Threatening Experiences & 6.41 & .08 & .19 & .0113 \\
Sense of Belonging-Psychological & 4.21 & .02 & -.33 & .0014 \\
Emotion-oriented Coping & 25.70 & .02 & .58 & .0001 \\
Task-oriented Coping & 12.42 & .02 & -.34 & .0004 \\
& & & & \\
\hline
\end{tabular}

Log-likelihood $=363.0, d f=14, p=.0001$. 
is popular in variable selection in medical and biological sciences and is considered useful when the number of subjects in each group is disproportionate; Clark and Pregibon (1992) emphasized that it is an exploratory technique for uncovering structure. "The models are fitted by binary recursive partitioning whereby a dataset is successively split into increasingly homogeneous subsets until it is infeasible to continue" (p. 377). The method used the disposition status as a dichotomous response and the pool of measures as explanatory variables to predict disposition status. It determined the sequence of a single explanatory variable to achieve the best result of response classification in terms of outside criteria such as misclassification rate or deviance of likelihood (Clark \& Pregibon, 1992).

The model resulted in depressed recruits who completed basic training, which were $100 \%$ correctly classified, had lower conflict scores, and no history of parental abuse. The addition of a third variable made minimal impact on correct classification of the depressed recruits. Thus, higher conflict in interpersonal relationships and a history of parental abuse were the strongest predictors for eventual separation.

\section{Discussion}

This study helps further the understanding of depression by examining young men and women who are placed in a new, stressful, unusual environment where many of their activities are similar and controlled. This controlled environment of basic training affords a unique opportunity to examine the factors associated with depression not obtainable in naturalistic civilian settings.

This study supports the general premise that childhood experiences and quality of life in the family can have a substantial impact on an individual's future functioning. Recruits' perceptions of themselves in relation to others through the experience of loneliness and sense of belonging seem to have a significant effect on their success in completing recruit training. Recruits' use of emotion-oriented rather than task-oriented coping appears to compromise their functioning in recruit training, as do more stressful life events prior to recruit training.

Recruits with depressive symptoms had significantly more predisposing problems including more family history of mental illness, more family history of alcohol abuse, and more history of psychiatric problems, supporting Hypothesis 1 . The reduced regression model identified $82 \%$ of the depressed recruits, and nearly $70 \%$ were correctly classified. Having some comparison recruits classified as false positives is less concerning since a large percentage of the depressed recruits were identified by the three predisposing factors. Family history of mood disorders is one of the primary risk factors for depression (Akiskal, 1989; Cigrang et al., 1998), and persons who develop Major Depressive Disorder before age 20 have a higher incidence of depression in their families (Goodwin \& Jamison, 1990). Of particular concern is that many of these recruits may have been unaware of their depressive symptoms as indicated by their endorsing few, if any, items that asked about depression on the SHIP and the HOI. While it is possible that some recruits underreported their depressive symptoms to avoid attention or potential separation from the Navy, specific in-processing strategies are designed to reduce this possibility through interviews by mental health technicians and close observations by the recruit training personnel.

Women who experience physical, emotional, or sexual abuse in their childhood may be at greater risk for depression later in life (Dansak, 1998; Hall, Sachs, Rayens, \& Lutenbacher, 1993). In this study, the effect remained the same for men and women recruits. Physical, emotional, or sexual abuse was a predisposing factor for both men and 
women with depressive symptoms. Likewise, consistent with our findings, a family history of alcohol abuse is related to the subsequent development of depression (Depression Guideline Panel, 1993; Helzer \& Pryzbeck, 1988).

A lack of social support and sense of belonging and high loneliness have been associated with a person's vulnerability to depression (Coyne \& Downey, 1991; Hagerty et al., 1992; Hagerty et al., 1996; Kessler \& McLeod, 1985; Peplau et al., 1979; Russell et al., 1984). Recruits with depressive symptoms perceived significantly less sense of belonging than the matched comparisons, which supports Hypothesis 2. Yet, Hagerty and Williams (1999) found that social support was not a significant predictor. Social support only had an indirect effect on depressive symptoms, but a lower sense of belonging had a much greater direct effect on depressive symptoms.

Recruits with depressive symptoms employed less effective coping strategies, thus lending support to Hypothesis 2 (Gulesserian \& Warren, 1987; Parker et al., 1986; Rippere, 1976). These coping strategies, such as more emotion-oriented and less taskoriented coping, may further arouse depressive or other negative affective responses, yet not help the recruit adapt any better to the stressful situation being encountered. Those recruits able to refocus their attention or actively manipulate their environment were more likely to better cope. Greater task-oriented coping involves the ability to use problem solving and focus on the task at hand.

Some episodes of depression occur in the absence of any notable stressor whereas others are clearly associated with life events. Paykel et al. (1969) found that depressed persons reported three times as many life-event stressors in the six months prior to the onset of the depression as nondepressed persons, albeit in this study depressed recruits had twice as many life-event stressors or threatening experiences than those without depression. In addition, recruits with depressive symptoms had significantly higher perceived global stress, although all encountered basically the same training conditions.

This study demonstrates that recruit training is a major life event. The recruits experienced highly structured and demanding expectations that created stress. Recruits were often leaving their childhood home for the first time, suffering the loss of their social support network including parents, siblings, friends, coworkers, and employers. It should be noted, however, that no causal interpretation between recruit training and the onset of depression could be made. As evidenced by the study data, some recruits in the depressed group had a history of psychiatric problems before arriving at recruit training. It is unclear to what extent recruit training exacerbated existing symptoms or generated depressive symptoms in these recruits.

Variables that predicted whether a depressed recruit would be separated or complete basic training were especially revealing of the nature of the human response to stressful conditions. It was apparent that interpersonal relatedness was critical in determining who would continue training versus who would forfeit a career in the Navy. Certainly the long-term difficulties cannot be underestimated when recruits come from an abusive background. Interpersonal conflicts and a history of abuse appear to be key for difficulties in career options and successes in the Navy. The need for teamwork in the Navy and the ability to relate to others are essential skills in completing recruit training.

Clinical implications of this study include the relevance of both the predisposing and concomitant factors that seemed to influence depression in the recruits. It is evident that predisposing childhood and family experiences are related to an individual's functioning when confronted with a major life stressor. Strategies that assist the recruit to connect these problems with current thoughts and feelings and to reframe these experiences may be useful in promoting successful recruit training. In addition, recruits can be helped to manage concomitant factors with strategies that promote task-oriented 
coping such as problem solving, cognitive reframing, and developing interpersonal connections.

This study provides an important examination of those factors that are associated with depression. Society has a number of ways of informing people about the risk factors for heart disease, for example, yet does little to inform people about the risk factors for depression, the most common mental illness. Understanding those predisposing factors and the concomitant factors such as the nature of the recruit's childhood experiences, interpersonal relationships, loneliness, sense of belonging, and coping may well illuminate interpersonal processes that are specifically related to a person's development of depression. It is possible to address predisposing childhood factors that are associated with the development of depressive symptoms, and interventions can be developed to target concomitant factors including loneliness, sense of belonging, effects of major life events, and use of task-oriented coping strategies.

\section{References}

Ainsworth, M.D.S. (1973). The development of infant-mother attachment. In B.M. Caldwell \& H.N. Ricciuti (Eds.), Review of child development research (Vol. 3, pp. 1-94). Chicago: University of Chicago Press.

Akiskal, H.S. (1989). New insights into the nature and heterogeneity of mood disorders. Journal of Clinical Psychiatry, 50(Suppl. 5), 6-12.

American Psychiatric Association. (1994). Diagnostic and statistical manual of mental disorders (4th ed.). Washington, DC: Author.

Beck, A.T., Steer, R.A., \& Brown, G.K. (1996). BDI-II manual. San Antonio, TX: The Psychological Corporation.

Billings, A., \& Moos, R.H. (1981). The role of coping resources in attenuating the impact of stressful life events. Journal of Behavioral Medicine, 4, 157-189.

Bloom, W. (1980). Air Force medical evaluation test (AFMET) identifies psychological problems early. USAF Medical Service Digest, 31, 8-9.

Bowlby, J. (1969). Attachment and loss: Vol. 1. Attachment. New York: Basic Books.

Bowlby, J. (1982). Attachment and loss: Vol. 1. Attachment (2nd ed.). New York: Basic Books.

Bragg, M.E. (1979). A comparative study of loneliness and depression. Unpublished doctoral dissertation, University of California, Los Angeles.

Breiman, L., Friedman, J.H., Olshen, R., \& Stone, C.J. (1984). Classification and regression trees. Belmont, CA: Wadworth.

Brugha, T.S., \& Cragg, D. (1990). The list of threatening experiences: The reliability and validity of a brief life events questionnaire. Acta Psychiatrica Scandinavica, 82, 77-81.

Cigrang, J.A., Carbone, E.G., Todd, S., \& Fiedler, E. (1998). Mental health attrition from Air Force basic military training. Military Medicine, 163, 834-838.

Clark, L.A., \& Pregibon, D. (1992). Tree based models. In J.M. Chambers \& T.J. Hastie (Eds.), Statistical models in S (pp. 377-419). Pacific Grove, CA: Wadsworth \& Brooks.

Cohen, J. (1960). A coefficient of agreement for nominal scales. Educational and Psychological Measurement, 20, 37-46.

Cohen, S., Kamarck, T., \& Mermelstein, R. (1983). A global measure of perceived stress. Journal of Health and Social Behavior, 24, 385-396.

Cornelis, C.M., Armeling, E.H., \& deJonghe, F. (1989). Life events and social network in relation to onset of depression: A controlled study. Acta Psychiatrica Scandinavica, 80, 174-179.

Coyne, J.C., \& Downey, G. (1991). Social factors and psychopathology: Stress, social support, and coping processes. Annual Review of Psychology, 42, 401-425. 
Crawford, S.L., \& Fiedler, E.R. (1991). Development and current status of USAF mental health screening. Military Medicine, 156, 596-599.

Dansak, D.A. (1998). Childhood abuse and parental disorders reported by Navy outpatient mental health patients. Military Medicine, 163, 510-514.

Depression Guideline Panel. (1993). Depression in primary care: Vol. 1. Detection and diagnosis. Rockville, MD: Agency for Health Care Policy and Research.

Endler, N.S., \& Parker, M.A. (1990a). CISS: Coping inventory for stressful situations manual. North Tonawanda, NY: Multi-Health Systems.

Endler, N.S., \& Parker, M.A. (1990b). Multidimensional assessment of coping: A critical evaluation. Journal of Personality and Social Psychology, 58, 844-854.

Feeney, J.A., Noller, P., \& Hanrahan, M. (1994). Assessing adult attachment. In M.B. Sperling \& W.H. Berman (Eds.), Attachment in adults (pp. 128-152). New York: Guilford Press.

First, M.B., Gibbon, M., Spitzer, R.L., Williams, J.B.W., \& Benjamin, L.S. (1997). Structured clinical interview for DSM-IV: CAS II (computer assisted SCID II). North Tonawanda, NY: Multi-Health Systems, Inc. \& American Psychiatric Press.

First, M.B., Gibbon, M., Williams, J.B.W., \& Spitzer, R.L. (1995). Mini-SCID (for DSM-IV) Version 2. User's manual. North Tonawanda, NY: Multi-Health Systems \& American Psychiatric Press.

First, M.B., \& Multi-Health Systems Staff. (1996). GAF Report: For the Global Assessment of Functioning Scale. North Tonawanda, NY: Multi-Health Systems.

Ganster, D.C., \& Victor, B. (1988). The impact of social support on mental and physical health. British Journal of Medical Psychology, 61, 17-36.

Gershon, S. (1991). Depression: Patient profile and treatment options confront issues with the experts. Journal of Clinical Psychiatry, 52, 437-444.

Goodwin, F.K., \& Jamison, K.R. (1990). Manic-depressive illness. New York: Oxford University Press.

Gulesserian, B., \& Warren, C.J. (1987). Coping resources of depressed patients. Archives of Psychiatric Nursing, 1, 392-398.

Hagerty, B.M.K., Lynch-Sauer, J., Patusky, K., Bouwsema, M., \& Collier, P. (1992). Sense of belonging: A vital mental health concept. Archives of Psychiatric Nursing, 6, 172-177.

Hagerty, B.M.K., \& Patusky, K.L. (1995). Developing a measure of sense of belonging. Nursing Research, 44, 9-13.

Hagerty, B.M.K., \& Williams, R.A. (1999). The effects of sense of belonging, social support, conflict, and loneliness on depression. Nursing Research, 48, 215-219.

Hagerty, B.M.K., Williams, R.A., Coyne, J.C., \& Early, M.R. (1996). Sense of belonging and indicators of psychological and social functioning. Archives of Psychiatric Nursing, 10, 235-244.

Hall, R.C.W. (1995). Global Assessment of Functioning: A modified scale. Psychosomatics, 36, 267-275.

Hall, L., Sachs, B., Rayens, M., \& Lutenbacher, M. (1993). Childhood physical and sexual abuse: Their relationship with depressive symptoms in adulthood. Image, 25, 317-321.

Helzer, J.E., \& Pryzbeck, T.R. (1988). The co-occurrence of alcoholism with other psychiatric disorders in the general population and its impact on treatment. Journal of Studies of Alcohol, 49, 219-224.

Holmes, T.H., \& Rahe, R.H. (1967). The Social Readjustment Rating Scale. Journal of Psychosomatic Research, 11, 213-218.

House, J.S., \& Kahn, R.L. (1985). Measures and concepts of social support. In S. Cohen \& L. Syme (Eds.), Social support and health (pp. 83-106). New York: Academic Press.

Jones, S.H., Thornicroft, G., Coffey, M., \& Dunn, G. (1995). A brief mental health outcome scale: Reliability and validity of the Global Assessment of Functioning (GAF). British Journal of Psychiatry, 166, 654-659. 
Kessler, R.C., McGonagle, K.A., Zhao, S., Nelson, C.B., Hughes, M., Eshleman, S., Wittchen, H.-U., \& Kendler, K.S. (1994). Lifetime and 12-months prevalence of DSM-III-R psychiatric disorders from in the United States: Results from the national comorbidity survey. Archives of General Psychiatry, 51, 8-19.

Kessler, R.C., \& McLeod, J.D. (1985). Social support and mental health in community studies. In S. Cohen \& L. Syme (Eds.), Social support and health (pp. 219-238). New York: Academic Press.

Klerman, G.L., \& Weissman, M.M. (1992). The course, morbidity, and costs of depression. Archives of General Psychiatry, 49, 831-833.

Lachar, D., Sparks, J.C., Larsen, R.M., \& Bisbee, C.T. (1974). Psychometric prediction of behavioral criteria of adaptation for USAF basic trainees. Journal of Community Psychology, 2, 268-277.

Loranger, A.W. (1988). The Personality Disorder Examination (PDE) Manual. Yonkers, NY: DV Communications.

Monroe, S.M., \& Depue, R.A. (1991). Life stress and depression. In J. Becker \& A. Kleinman (Eds.), Psychosocial aspects of depression. Hillsdale, NJ: Erlbaum.

Naval Hospital, Great Lakes. (1998). SHIP: In-processing screening questionnaire. Great Lakes, IL: Author.

Parker, G., Brown, L., \& Blignault, I. (1986). Coping behaviors as predictors of the course of clinical depression. Archives of General Psychiatry, 43, 561-565.

Paykel, E.S. (1994). Life events, social support, and depression. Acta Psychiatrica Scandinavica, Vol. 377, 50-58.

Paykel, E.S., Meyers, J.K., Dienelt, M.N., Klerman, K.G., Lindenthal, J.J., \& Pepper, M.P. (1969). Life events and depression. Archives of General Psychiatry, 21, 753-760.

Peplau, L.A., Russell, D., \& Heim, M. (1979). The experience of loneliness. In I.H. Frieze, D. Bar-Tal, \& J.S. Carroll (Eds.), New approaches to social problems: Applications of attribution theory (pp. 53-78). San Francisco: Jossey-Bass.

Rawlings, J.O. (1988). Applied regression analysis. CA: Wadsworth \& Brooks/Cole.

Rippere, V. (1976). Antidepressive behavior: A preliminary report. Behavior Research \& Therapy, 14, 289-299.

Robins, L.N., Helzer, J.E., Croughan, J., \& Ratcliff, K.S. (1981). National Institute of Mental Health diagnostic interview schedule. Archives of General Psychiatry, 38, 381-389.

Roy-Byrne, P., Dagadakis, C., Unutzer, J., \& Ries, R. (1996). Evidence for limited validity of the revised Global Assessment of Functioning scale. Psychiatric Services, 47, 864-866.

Russell, D., Cutrona, C.E., Rose, J., \& Yurko, K. (1984). Social and emotional loneliness: An examination of Weiss's typology of loneliness. Journal of Personality and Social Psychology, 46, 1313-1321.

Sarason, B.R., Sarason, I.G., \& Pierce, G.R. (1990). Traditional views of social support and their impact on assessment. In B.R. Sarason, I.G. Sarason, \& G.R. Pierce (Eds.), Social support: An interactional view (pp. 9-21). New York: Wiley.

Segal, D.L., Hersen, M., \& Van Hasselt, B. (1994). Reliability of the structured clinical interview for DSM-III-R: An evaluative review. Comprehensive Psychiatry, 35, 316-327.

Skodol, A.E., Rosnick, L., Kellman, D., Oldham, J.M., \& Hyler, S.E. (1988). Validating structured DSM-III-R personality disorder assessments with longitudinal data. American Journal of Psychiatry, 145, 1297-1299.

Spitzer, R.L., Williams, J.B.W., Gibbon, M., \& First, M.B. (1990). SCID: User's guide for the structured clinical interview for DSM-III-R. Washington, DC: American Psychiatric Press.

Stuart, G.W. (1998). The Stuart stress adaptation model of psychiatric nursing care. In G.W. Stuart \& M.T. Laraia (Eds.), Principles and practice of psychiatric nursing (6th ed., pp. 66-81). St. Louis: Mosby. 
Tilden, V.P., Nelson, C., \& May, B.A. (1990). The Interpersonal Relationships (IPR) Inventory: Development and psychometric characteristics. Nursing Research, 39, 337-343.

Warner, V., Weissman, M.M., Fendrich, M., Wickramaratne, P., \& Moreau, D. (1992). The course of major depression in the offspring of depressed parents. Archives of General Psychiatry, 49, 795-801.

Weinstein, M.C., \& Fineberg, H.V. (1980). Clinical decision analysis. Philadelphia: Saunders.

Weiss, R.S. (1973). Loneliness: The experience of emotional and social isolation. Cambridge, MA: MIT Press.

Wenz, F.V. (1977). Seasonal suicide attempts and forms of loneliness. Psychological Reports, 40, 807-810.

West, D.A., Kellner, R., \& Moore-West, M. (1986). The effects of loneliness: A review of the literature. Comprehensive Psychiatry, 27, 351-363.

Williams, J.B., Gibbon, M., First, M.B., Spitzer, R.L., Davies, M., Borus, J., Howes, M.J., Kane, J., Pope, H.G., Rounsaville, B., \& Wittchen, H. (1992). The structured clinical interview for DSM-IIIR (SCID). Part II: Multisite test-retest reliability. Archives of General Psychiatry, 49, 630-636. 